\title{
Acacia Ferrugenia Reinforced Polyester Composites
}

\author{
Ragul Kumar S., Winowlin Jappes J. T., Siva I., Brintha N. C.
}

\begin{abstract}
Fiber Reinforced Polymer composites are widely used in light weight automotive components. In this research work, the mechanical properties of acacia/polyester composites were studied. The composites were prepared in 10 and $20 \mathrm{wt} \%$ varying fiber loading, treated and untreated compositions using compression molding technique. The composites were tested for mechanical properties and their results were studied. The results indicated that the $10 w t \%$, treated Acacia ferrugenia/polyester composites showed better fire resistivity and high energy absorption characteristics.
\end{abstract}

Keywords: Acacia ferrugenia, Polyester, Compression molding, Mechanical properties.

\section{INTRODUCTION}

Light weighting of automobiles has become more vital due to numerous environmental issues. For the purpose of increasing the fuel efficiency, engine performance, vehicle safety conditions, and to lower emissions, the vehicle weight is the key factor. The global automotive industry is transforming to light weight automotive components. This light weighting concept is an essential thing for the future promising electric / hybrid automotive vehicles. Various new materials can be used to make light weight automotive vehicle components to replace those heavy metal components [1]. Polymer is a large group of molecule with broad range of properties. The multi diversity behavior of polymers has made its application in various fields. Both synthetic and natural polymers play a vital role in day to day life. Synthetic polymers has an edge over natural polymers as they can be restructured according to the application. Polymer Matrix Composites are so popular due to their reduced cost and easier manufacturing methods. Commercially manufactured Polymer Matrix Composites consists of a Resin solution. Polyester resins are widely used in automotive and maritime applications. The unsaturated polyester resin is a thermoset, which has the capability to get cured from liquid or solid

Revised Manuscript Received on December 29, 2019.

* Correspondence Author

Ragul Kumar S, Centre for Composite Materials, Department of Mechanical Engineering, Kalasalingam Academy of Research \& Education, Virudhunagar, Tamilnadu, India Email: rakulkumarsrk14@gmail.com.

Winowlin Jappes J T*, Centre for Composite Materials, Department of Mechanical Engineering, Kalasalingam Academy of Research \& Education, Virudhunagar, Tamilnadu, India Email: winowlin@klu.ac.in

Siva I, Centre for Composite Materials, Department of Mechanical Engineering, Kalasalingam Academy of Research \& Education, Virudhunagar, Tamilnadu, India, Email: isiva@klu.ac.in

Brintha N C, Department of Computer Science and Engineering, Kalasalingam Academy of Research and Education, Virudhunagar, Tamilnadu, India. Email: brinthachris2k@gmail.com state. The big advantage of this unsaturated polyester resin is its balance of properties such as mechanical, chemical, electrical, dimensional stability, cost and ease of handling and processing. The increase in environmental awareness and interest in saving the nature, the research focus has now changed to the use of environmental friendly materials. Natural fibers are one such material. The fibers are not synthetic or manmade. Previously, various authors revealed the characters of natural fibers declared the ability of those fibers to be used as reinforcement on polymer composites [2-7]. Even though, these types of reinforcement have some difficulties in fiber and matrix bonding problem, due to difference in native characteristics of those fibers and polymers. And also, a major threat to these type of composites is the age, weather, the origin of the plant fiber and the method of extraction. But, mostly these type of difficulties can be solved by surface modification [8-11]. It is done by chemical treatments in order to improve the physical and chemical properties. The mechanical properties of a polymer composite are determined by the effect of fiber loading, fiber length and surface modification.

The reinforcement of acacia ferrugenia fibers which were extracted from acacia bark, with polyester has not been investigated till date. The previous studies of these fibers and optimum properties were obtained when these fibers were 5 wt $\%$ of $\mathrm{NaOH}$ solution for 30 minutes. This study focuses on the mechanical properties of treated and untreated of Acacia ferrugenia / Polyester composites.

\section{EXPERIMENTAL DETAILS}

\section{A. Acacia Ferrugenia fiber extraction and treatment}

Acacia treated with $\mathrm{NaOH}$ solution in polyester have increase mechanical and thermal properties. The acacia plant stems were collected from the acacia tree along the roadside. The stems were then cleaned for any impurities. Those stems are then soaked in water for removing dirt and other impurities and kept undisturbed for about 10 days. This separates the Acacia Ferrugenia fibers from the stems of the plant.

After the fibers extraction, the fibers are dried and then prepared for chemical treatment for surface modification. The fibers are split and weighed for $10 \mathrm{wt} \%$ and $20 \mathrm{wt} \%$ of polyester. The $\mathrm{NaOH}$ solution is filled in a tray and the extracted fibers were dipped in $\mathrm{NaOH}$ solution for about 1 hour and then dried in direct sunlight. 


\section{B. Fabrication of Composites}

The Acacia ferrugenia / Polyester composites are fabricated using Compression molding, with a mold size of about $300 \times 300 \times 3 \mathrm{~mm} 3$. In order to get the samples out of the mold easily, wax was applied over the mold layers before filling it with fibers and polyester resin, for fabrication of the composite samples. Ten composite samples were prepared by varying the fiber content (10 wt $\%$ and $20 \mathrm{wt} \%)$ and chemical treatment (1N NaOH, and Untreated). The Acacia Ferrugenia fiber weight was measured before fabrication and the polyester was mixed with the hardener in the ratio of 10:1 by weight. A mechanical stirrer was used to get a uniform mixture of polyester. Then it was filled in the mold which contains the fibers. The setup is placed in the compression molding machine and compressed at about $100 \mathrm{MPa}$ constant pressures and allowed to cure for about 10 hours at room temperature.

\section{Impact Testing}

The impact specimens of Acacia ferrugenia/polyester composites were prepared according to ASTM D256 standards using an Izod digital Impact tester. The unnotched composite samples were placed around a cantilever position. A pendulum of about $3 \mathrm{Kg}$, at a velocity of about $3.562 \mathrm{~m} / \mathrm{s}$, was made to break through the sample and the corresponding Impact energy was observed through the digital gauge on the machine. Four composite samples were tested and their average was taken.

\section{Flammability testing}

The flammability test was performed as per the ASTM D4804-19 Standard. The flammability testing is conducted to determine the fire resistance capability of the composite samples. The flammability testing involves a typical flammability tester. It consists of a gas inlet, burner and the sample holder. A typical commercial LPG cylinder was used as the gas source. Initially, the gas burner was configured for blue flame. The composite sample to be tested is placed on the holder and is fired up. The time taken for the flame to travel up to a $25 \mathrm{~mm}$ distance on the sample is noted down from the digital timer that was fitted on the instrument. Similarly, the distance covered by the fire in a time period of 30 seconds is also calculated.

\section{E. Wear testing}

The wear test was done with a pin on disc wear tester instrument. The test was conducted as per ASTM G-99 standard. The wear tester was run three times for a time period of about 30 minutes, for each set of composite samples. The ambient temperature was about $23^{\circ} \mathrm{C}$ and relative humidity was about $50 \%$. The composite samples were prepared according to the specimen size of about $10 \mathrm{~mm}$ x $10 \mathrm{~mm}$ x $3 \mathrm{~mm}$. The samples were placed in contact with the hardened alloy steel disc. The hardened steel disc has a hardness value of $62 \mathrm{HRC}$. It has a surface roughness of about $0.54 \mu \mathrm{m}$. The composite samples are placed in a position that the rotating counter body is perpendicular to the thickness of the sample. The test parameters are : A normal load of about $10 \mathrm{~N}$ is assigned constant for all set of wear test samples and the sliding velocities were $3 \mathrm{~m} / \mathrm{s}, 4 \mathrm{~m} / \mathrm{s}$ and $5 \mathrm{~m} / \mathrm{s}$ for the maximum sliding distance of about $3000 \mathrm{~m}$ steps of $300 \mathrm{~m}$. Before proceeding with the test, the samples were wiped using a silicon carbide paper in order to get a proper flat surface contact with the rotating counter face of the disc. Initially, the sample to be tested is weighed to an accuracy of $0.0001 \mathrm{~g}$, along with the pin assembly, in an electronic balance. The difference between the initial and the final mass of the composite samples before and after the wear test run gives the sliding wear loss of those composite samples.

\section{RESULTS AND DISCUSSION}

\section{A. Impact Properties}

The effect of fiber loading and surface modification of the Acacia ferrugenia / polyester composites is shown in fig. 1. It is observed from the fig. 1 that the impact strength of the treated and untreated acacia ferrugenia/polyester fiber composites increase with the surface modifications while increasing the fiber content decrease the impact strength. This may be due to the limited character of fibers being able to absorb energy up to a certain amount of energy only. A similar trend of result was observed by Manikandan and Winowlin Jappes [8].

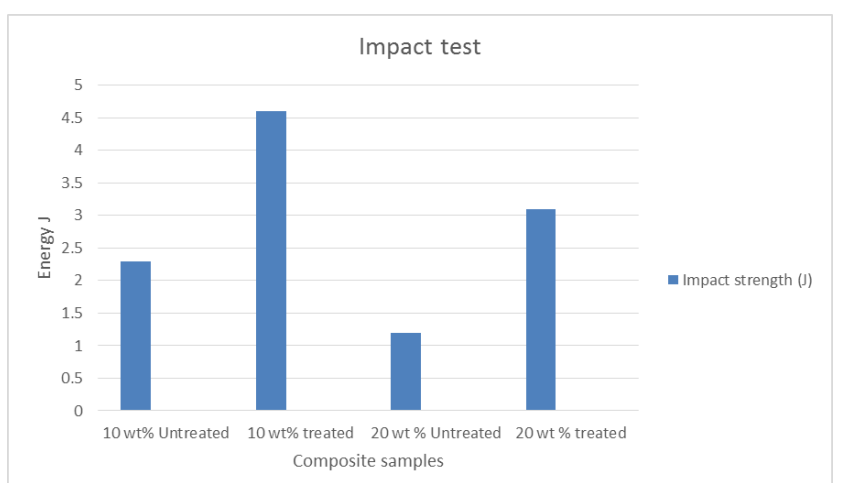

Fig. 1: Impact property

\section{B. Flammability properties}

The flammability properties of Acacia ferrugenia/polyester composites are shown in fig. 2. It can be observed that $10 \mathrm{wt} \%$ treated Acacia/polyester composite samples possessed better fire resistivity characteristics. It is clear from the fig. 2 that the composite samples have good fire resisting property when they are treated. But the increase in fiber content, reduced their fire resisting characteristics. This may be due to the increased fiber content. A similar trend of result was observed and reported by Dorez and Taguet [13], respectively. 


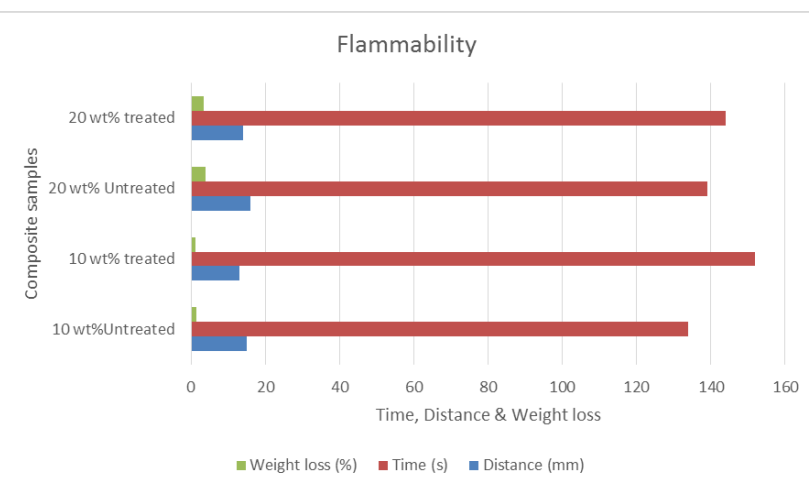

Fig. 2: Flammability property

\section{Wear testing}

The wear testing results can be obtained from table 1 . It is observed that $20 \mathrm{wt} \%$ treated Acacia ferrugenia/polyester composite samples possess reduced mass loss. For both 10 $\mathrm{wt} \%$ and $20 \mathrm{wt} \%$ treated composites the mass loss increases with increase in load and sliding velocity. Mohanty et.al [14] investigated on the effect of fiber content on abrasive wear testing and found that with the increase of sliding velocity and load the mass loss is increased it is confirmed in our study.

Table 1: Observation on Wear Test

\begin{tabular}{|l|l|l|l|l|}
\hline S.No & $\begin{array}{l}\text { Load } \\
(\mathbf{N})\end{array}$ & $\begin{array}{l}\text { Sliding } \\
\text { velocity } \\
(\mathbf{m} / \mathbf{s})\end{array}$ & $\begin{array}{l}\text { Treated } \\
\text { Sample } \\
\text { wt \% }\end{array}$ & Mass loss \\
\hline 1 & 10 & 4 & 10 & 0.0011 \\
\hline 2 & 10 & 4 & 20 & 0.0009 \\
\hline 3 & 20 & 4 & 10 & 0.0013 \\
\hline 4 & 20 & 4 & 20 & 0.0012 \\
\hline 5 & 30 & 4 & 10 & 0.0023 \\
\hline 6 & 30 & 4 & 20 & 0.0020 \\
\hline 7 & 10 & 5 & 10 & 0.0020 \\
\hline 8 & 10 & 5 & 20 & 0.0018 \\
\hline 9 & 20 & 5 & 10 & 0.0023 \\
\hline 10 & 20 & 5 & 20 & 0.0021 \\
\hline 11 & 30 & 5 & 10 & 0.0029 \\
\hline 12 & 30 & 5 & 20 & 0.0027 \\
\hline 13 & 10 & 3 & 10 & 0.0003 \\
\hline 14 & 10 & 3 & 20 & 0.0002 \\
\hline 15 & 20 & 3 & 10 & 0.0009 \\
\hline 16 & 20 & 3 & 20 & 0.0006 \\
\hline 17 & 30 & 3 & 10 & 0.0008 \\
\hline 18 & 30 & 3 & 20 & 0.0007 \\
\hline
\end{tabular}

\section{CONCLUSION}

From the mechanical characterization conducted for the Acacia ferrugenia/polyester composite samples, the following conclusions were made,

The 10 wt $\% 1 \mathrm{~N}$ treated, Acacia ferrugenia/polyester composites possessed much Impact strength and fire resisting properties whereas, the 20 wt $\%$ treated Acacia ferrugenia/polyester composites had reduced mass loss by sliding wear test method.

\section{REFERENCES}

1. Min-Young Lyu andTae Gyun Choi, "Research Trends in Polymer Materials for Use in Lightweight Vehicles", International Journal of precision engineering and manufacturing,(2015), vol. 16, no. 1, pp. 213-220

2. UK Rokeya, M Akter Hossain, M Rowson Ali, SP Paul, "Physical and mechanical properties of (Acacia auriculiformis x A mangium) hybrid Acacia”, Journal of Bangladesh Academy of Sciences, Vol 34, pp. 2.
3. M. Kumar, B. Verma, R. C. Gupta, "Mechanical Properties of Acacia and Eucalyptus Wood Chars", Energy Sources, vol 21, pp. 675-685

4. Mohd Hamami Sahri, Zaidon Ashaari, Razali Abdul Kader And Abdul Latif Mohmod, "Physical And Mechanical Properties of Acacia mangium and Acacia Auriculiformis from Different Provenances", PertanikaJ. Trap. Agric. Sci, Vol 21(2), pp. $73-81$

5. Alejandro Brenes-Acosta, Benito A. Stradi-Granados, "Comparative study of the mechanical properties of polyester resin with and without reinforcement with fiber-glass and furcraea cabuya fibers", Fibers and Polymers, Vol 15 (2015), pp. 2186-2192

6. F. Suhara, S. K. N. Kutty, G. B. Nando, "Mechanical Properties of Short Polyester Fiber Polyurethane Elastomer Composite with Different Interracial Bonding Agents", Polymer-Plastics Technology and Engineering, Vol 37, pp.241-252

7. L. Uma devi, s. S. Bhagawan, Sabu thomas, "Mechanical Properties of Pineapple Leaf Fiber-Reinforced Polyester Composites", Applied Polymer Science, Vol 64 (1998), pp.1739-1748.

8. V. Manikandan, J.T. Winowlin Jappes, S.M. Suresh Kumar, P. Amuthakkannan, "Investigation of the effect of surface modifications on the mechanical properties of basalt fibre reinforced polymer composites", Composites, (2012), Vol 43, pp. 812-818

9. V. P. Arthanarieswaran, A. Kumaravel, M. Kathirselvam \& S. S. Saravanakumar, "Mechanical and Thermal Properties of Acacia leucophloea Fiber/Epoxy Composites: Influence of Fiber Loading and Alkali Treatment", International Journal of Polymer analysis and Characterization", pp. 1563-5341

10. Ricardo Yoshimitsu Miyahara, Fábio Luiz Melquiades, Ezequiel Ligowski, Andressa do Santos, Silvia Luciana Fávaro, and Osmar dos Reis Antunes Junior, "Preparation and characterization of composites from plastic waste and sugar cane fiber", Polímeros, Vol 28 (2018), pp. 147-154.

11. Saravanakumar, S. S., A. Kumaravel, T. Nagarajan and I.G. Moorthy, "Investigation of Physico-Chemical Properties of Alkali-Treated Prosopis juliflora Fibers", International Journal Polymer Analysis Characteristics, Vol 19 (2014), 309-317.

12. Geethamma VG, Mathew KT, Lakshminarayanan R, Thomas S, "Composite of short coir fibers and natural rubber: effect of chemical modification, loading and orientation of fiber, Polymer Vol 39, (1998), 1483-1491.

13. G. Dorez, A. Taguet, L. Ferry, J.M. Lopez-Cuesta, "Thermal and fire behavior of natural fibers/PBS biocomposites", Polymer Degradation and Stability, (2013), Vol. 98, pp.87-95

14. Mohanty, J. R., Das, S. N., \& Das, H. C. (2014). Effect of fiber content on abrasive wear behavior of date palm leaf reinforced polyvinyl pyrrolidone composite. ISRN Tribology, 2014.

\section{AUTHORS PROFILE}

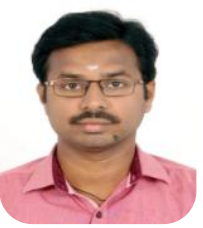

Mr. Ragul Kumar is obtained his bachelor degree in Mechanical Engineering in 2017 and he completed his Master of Technology in Automotive system engineering in 2019 from Kalasalingam Academy of Research and Education, Tamil Nadu.

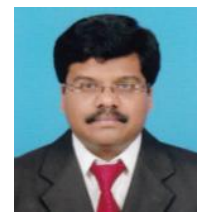

Dr. Winowlin Jappes J T graduated in 1997 from Manonmaniam Sunderanar University, India in Mechanical Engineering. In 1999, he has completed his masters in Production Engineering from Annamalai University. He completed his Ph.D degree in 2004 in the area of Composite Deposition at Indian Institute of Technology Madras, Chennai. He has completed three DST funded research projects and published more than 125 research articles which include 65 International Journal papers. Currently, he is working as Senior Professor in Kalasalingam University, India. His research interest includes high performance composite materials, machining of hard materials, optimization techniques, etc. At present, he is working as Professor and Dean, School of Automotive and Mechanical Engineering, Kalasalingam Academy of Research and Education, India.

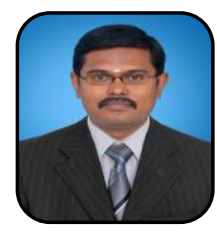

Dr. Siva I is obtained his Bachelors Degree in Mechanical Engineering in Mechanical Engineering from the Manonmaniam Sundaranar University, Tamilnadu/India (2002). 
In 2005 he acquired a Master's degree in Manufacturing Engineering by the Anna University, Tamilnadu/India and completed his $\mathrm{PhD}$ by the Department of Mechanical Engineering - Kalasalingam University/India (2012). He is currently a Visiting Researcher at the Federal University of Rio Grande do Sul/Brazil in the Department of Materials Engineering. He is leading an Indo-Brazil Centre for Composite Materials in Kalasalingam University/India. His area of expertise is Engineering Materials with the focus on processing natural fibers, bio-composite, fiber surface modification, interfacial analysis, wear and vibrational analysis of natural fiber composites. He received a BJT-B fellowship from $\mathrm{CNPq} / \mathrm{Brazil}$. Recently, he received a collaboration project between India and Brazil through DST/India and CNPq/Brazil.

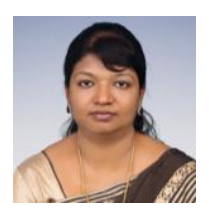

Dr. Brintha N C graduated in 2002 from Manonmaniam Sunderanar University, India. In 2006, she received her M.E Degree with distinction in Computer Science and Engineering from A.K.C.E, Anna University, Chennai. She completed her P.hd degree in 2018 in the area of Cloud Manufacturing under Anna University, Chennai. Currently, she is working as Associate professor/ CSE in Kalasalingam Academy of Research and Education, India. Her research interests include Cloud computing, Optimization, Scheduling, Cloud Manufacturing and so forth. 